\title{
The Development of Motion-Based Individual Badminton Smash Forehand Training Models for Students of IKIP Mataram 2019
}

\author{
Soemardiawan ${ }^{1,2^{*}}$, James Tangkudung ${ }^{2}$, Ahmad Sofyan Hanif ${ }^{2}$ \\ 1,2 Department of Education Management, IKIP Mataram, Mataram, Nusa Tenggara Barat, 83125, Indonesia \\ 2 Department of Sport Education, Universitas Negeri Jakarta, Jakarta Timur, 13220, Indonesia \\ umanksoemardiawan84@gmail.com \\ *Corresponding Author
}

How to Cite : Soemardiawan, S. Tangkudung, J., \& Hanif, A., S. (2019). The Development of Motion-Based Individual Badminton Smash Forehand Training Models for Students of IKIP Mataram 2019. International Journal for Educational and Vocational Studies, 1 (3), 177-183.

\section{ARTICLE HISTORY}

Received:3 May 2019

Revised: 23 June2019

Accepted: 29 July 2019

\section{KEYWORDS}

Model of Exercise;

Smash Forehand:

Individual;

Motion-Based;

Badminton

\begin{abstract}
This article produces a product in the form of an individual smash training model to improve the forehand smash capability which is based on good motion, has advantages over the previous model, where the model of individual smash forehand variations is to improve motion-based badminton Smash Skills. The aim to be achieved in development research is to produce a product program for individual smash forehand training which is efficiently and effectively varied, and also improve smash forehand skills, both in motion, technical skills, individually in the IKIP Mataram students. The population and samples using NTB athletes belonging to the UKM FPOK IKIP Mataram were 100 students. The instruments used in this development research were questionnaires, questionnaires, and the Badminton Smash Test Instrument from Purnama. The design of this study uses the research \& development (R \& D) development method of Borg and Gall which is qualitative in nature and while the quantitative approach is used to reveal the second objective, with a pre-experimental research design in the form of the one group pretest-posttest design. who looked for significant differences in individual forehand smash models before and after training were given a smash model. Based on the analysis of research data using the $t$ test with a significance level of 0.05 . Therefore, the research on the development of individual forehand smash models based on the results of badminton training from the results of research shows that the use of a varied and effective forehand smash training model can improve this forehand smash training model for badminton athletes in IKIP Mataram students.
\end{abstract}

This is an open access article under the CC-BY-SA license.

\section{INTRODUCTION}

The Badminton World Federation (BWF) estimated that about 200 million people of all ages and levels play the game worldwide. Badminton is a highly dynamic sport with the shuttlecock being struck at over $300 \mathrm{~km} / \mathrm{h}$. The BWF coaches' manual states that players are required to have a high level of motor coordination, However, previous studies that targeted sports activity did not include ball games because the motion of player is influenced by the motion of the opponent player or by the return ball by the opponent player.

Although we could not integrate the player's motion exactly as in ball games, we thought that was important to assess the muscle coordination pattern for the improve- ment of competitiveness. Thus, the purpose of this study was to investigate whether muscle synergy during overhead stroke in badminton depends on the competition level. If we could clarify the factor to improve the performance using synergy analysis in this study, synergy analysis may help not only badminton but also any other ball game the plan of training program to improve the performance, (Matsunaga N. at al. 2018:6).

Badminton is the most favourite sport in Indonesia. Since elementary school or earlier, children play badminton in a formal class or informal games, Muhammad Ilhamdi Rusydi, at al, (2015:898). Badminton is one of the most popular sports in Asia, especially in Indonesia.There aremany reasons why badminton is 
popular, for example, it can improve physical and mental health, it has fairly low injury risks, it is easy to play, racquet used is very durable and most importantly, all ages can play this sport. Badminton is a sport that requires high functionality of the shoulder, especially the movement and strength of the shoulder. This study was aimed to discover if playing badminton can improve shoulder strength, Feng, at.,al, (2017:208)

Badminton is one of the most popular sports in the world [1] and is a fast racket game characterized by high-intensity, intermittent actions [2]. The badminton players' performance is determined by the relationship of speed, agility, flexibility, shoulder strength, explosive strength, and muscular endurance [1]. The badminton forehand overhead techniques could be divided into three strokes: drop, clear, and smash [3]; the stroke can be divided into clear, drop, smash, block, lift, push, net, and dab [4]. The forehand overhead stroke is regarded as the fundamental to play badminton [5]. The clear strokes are among the most common strokes in badminton which account for $14-16 \%$ of the total stroke of the male players [6]. Clear strokes provide the basis of playing the shuttle from the players' own backline to the opponent's backline and are an overhead shot with a flat (offensive clear) or rising trajectory (defensive clear) towards the back of the opponent's court [1]. A good lift shot, like the type of clear stroke, which reaches the baseline of the rear court, sometimes helps the player to win the rally by causing misjudgement by the opposition player and allows the player to get more time to prepare for the next shot [4]. There is a lack of scientific research in badminton, including biomechanical investigations of stroke techniques [7]. (Xiaoxue Zhao and Shudong Li, 2018:8).

Based on observations from field observations, in badminton players in NTB that in FPOK IKIP Mataram students, researchers found the focus of problems in doing badminton smashes, both individually. that almost the majority of players are in forehand smash in terms of accuracy, direction, and accuracy. It can be seen from the lack of badminton smash variations that are performed, not in accordance with the basic motion. This will be a solution for the world of badminton. Overhead smash badminton forehand is one of high speed and strong movements among various racquet sports.

The badminton forehand overhead smash is one of the high speed and powerful motions among various racket sports [1]. Badminton is a sport that requires a lot of overhead shoulder movement, with the shoulder in abduction and external rotation and generally proximal-to-distal sequence, Barnamehei, Hamidreza , at al., $(2018,10)$.

The main purpose of this study was to construct and validate a motion equation for the flight of the badminton and to find the relationship between the air resistance force and a shuttlecock's speed, Lung-Ming Chen, at.,al, (2009:657).
In the purpose of this research is to produce a product in the form of a forehand smash training model that is carried out individually in order to improve the motion-based smash forehand ability, and the optimal has the advantages of the previous model, where the resulting model has more smash variations to improve the ability of badminton Smash according to basic motion. The target to be achieved in this development research is to produce a product of an efficient and effective smash training program to improve individual smash forehand abilities, multiply badminton smash forehand variation techniques, and produce a model product

Badminton smash forehand training, based on basic motion individually. So as to provide more knowledge about smash forehand smash individually on IKIP Mataram students and basic motion techniques for smash blows to improve the forehand smash, on the individual smash training model. Badminton is a racquet sport that is played by two people (for singles), or two pairs (for doubles) that take opposite positions in the field divided by a net (net), (Aksan, 2013:14).

\section{METHODS}

\subsection{Development}

Research and development (reseearch and development / R \& D) according to Borg and Gall in Sugiyono (2008:9), states that research and development is a research method used to develop or validate products that will be used in education and learning. Research and development can also be used to assess a product in teaching and learning activities. Can the product be used in the world of education or must be revised to be used,).

\subsection{Models}

The model is a framework and structure that arose in the special field, developed, and then used in another area. This model is the analogy or metaphor that conducts research and thinking. For example, in experimental studies, nervous system is likened to a telephone system or eye is likened to the camera. Models enable us to more fully understand complex concepts, and ultimately, testing the model can further enhance our knowledge and understanding of our own behavior (Payne \& Isaacs, 2011). Sayed Kavos Saleh, at., al. 2017:217)

Bompa in Roesdiyanto and Budiwanto stated that the model is an imitation, an imitation of the original, arranges a special part of a phenomenon that is observed or investigated. It is also a type of isomorphous shadow (similar to the form of a match), which is observed through abstraction, a mental process generalizing from a concrete example. During creating a model, arranging hypotheses is very important for change and produces analysis. Roesdiyanto and Setyo Budiwanto, 2008). 


\subsection{Training}

The training derived from the word training is a process of perfecting sports skills that contains material theory and practice using methods, and rules of practice with a scientific approach using the principles of planned and orderly training, so that the training objectives can be achieved on time. One characteristic of good practice that comes from the word practice, exercise, and training is the training load. The training load is a motoric stimulation of motion that can be regulated and controlled by any trainer to improve the functional quality of various body equipment.

Michal Wilk, at., al. (2019:191), Training at a specific movement tempo is a relatively new concept in resistance training. It is based on manipulation of the duration of particular phases of a movement. General studies have demonstrated that faster movement tempo in resistance training leads to an increase in muscle power, whereas lower movement speed is beneficial in the development of muscle strength and hypertrophy. The main finding of the study indicates that the duration of the eccentric phase of the movement has a significant impact on muscular power and velocity during the concentric phase of the movement.

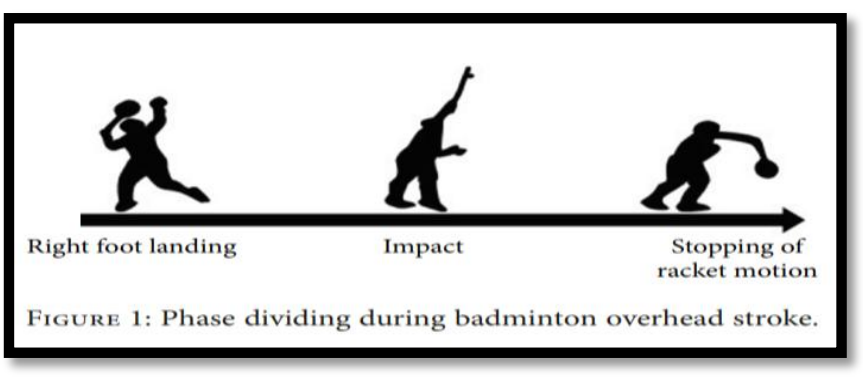

Figure 1. Phase during an Overhead Stroke, Journal Matsunaga N. at al. (2018: 6).

\subsection{Smash forehand}

One of the dominant skills in badminton is overhead forehand, which consists of 1/5 attacks during a match. Empirical evidence shows that one must adjust the position of the body in relation to how come to produce a strong and accurate smash. Therefore, positioning is a fundamental aspect that affects the quality of the smash. (Shiming Li, at 2016: 28).

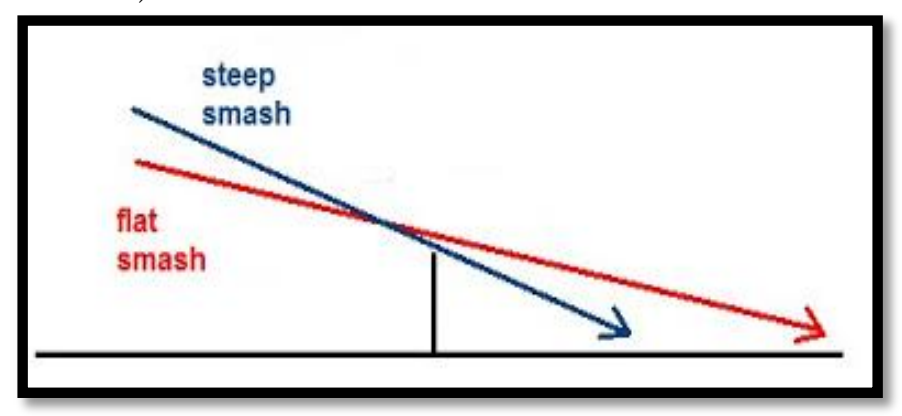

Figure 2. Movement when smash forehand, Punkh, 2013.
The forehand overhead smash is similar to the action of throwing a ball. If you can throw a ball well, you shouldn't have problem playing this stroke (Yap, 2012). The forehand overhead smash is regarded as the most powerful stroke of all forehand overhead strokes such as the clear and drop strokes seen in Figure 2 (Jaitner \& Gawin, 2010; Kwan, Andersen, de Zee, \& Rasmussen, 2008; Salim, Lim, Salim, \& Baharuddin, 2010). In addition, Abe and Okamoto (1989), and Lo and Stark (1991) point out that the 8 smash is a powerful offensive weapon due to the power and speed (Sakurai \& Ohtsuki, 2000). In respect to smash shuttle velocity, the IBF stated on its official website that badminton could firmly stake its claim as the world's fastest racket sport (Hussain, Paul, \& Bari, 2011 The Forehand Overhead Smash Badminton offers a wide variety of basic strokes, and players require a high level of skill to perform all of them effectively. The hitting areas (see Figure 1) where the player can reach the shuttle most easily can be roughly divided into the forehand and backhand. The numbers in the figure distinguish between side hand, underhand and overhand; which refer to shuttles hit at the side of the body, at knee/foot level, shoulder level or over the head respectively. Brahms (2014) pointed out that about $75 \%$ of a player's range is in the forehand area and about $25 \%$ is in the backhand, (Zhao Zhang. 2012:5)

Advantages of Overhead Forehand The Advantages of the Forehand Overhead Smash Throughout badminton's technical development, the smash has been used as a common stroke for scoring and has become a necessity and favourite for both amateurs and professionals. In addition, no stroke in the game of badminton is as spectacular and aggressive as the smash (Zhao, 2007). Because the power of a forehand overhead smash has one of the highest tip-speed motions among various hitting motions of all racket sports, it has become the standard of judgment regarding a player's technique and skill (Koike \& Hashiguchi, 2014; Liu, Kim, \& Tan, 2010; Teu, Kim, Tan, \& Fuss, 2005; Yang, Dalam Thesis (Zhao Zhang. 2012: 13)

The Three Phases of Badminton Forehand Overhead Smash. The forehand overhead smash is one of the most effective and useful scoring techniques, however it is difficult for players to correctly master (Yang, 2013). The first step is for players to have a detailed understanding of each movement required to achieve the smash. Understanding the basic characteristics of the smash action is best achieved through a combination of teaching principles and experiences of coaches and teachers, and the analysis of action principles obtained from scientists (Yang, 2013). Today, the most common technique used in smash instruction is described by dividing the method into three action phases: preparation, acceleration (back-swing and forward-swing), and follow-through (Brahms, 2014; "How to hit", 2014; Yang, 2013; Yap, 2012). Figure 3 displays each stage of the badminton smash for a right-handed player shown in the laboratory setting. Each stage will be clearly presented and explained for a 
right-handed player. It is worth noting that there are slight differences between smash and jump smash effectiveness (Hong \& Tong, 2000; Jaitner \& Gawin, 2010). However, these will also be described in the following section.

\subsubsection{PreparationPhase}

The smash begins where the player decides to contact the shuttlecock (Yang, 2013). Empirical evidence shows that during a game, no matter what type of smash the player could apply, the player must first adjust his/her body positioning in relation to the incoming shuttlecock in order to produce a powerful and accurate smash (Brundle, 1963; Davidson \& Gustavson, 1964; Zhao, 2007). In the preparation phase, a series of actions are done to lead to an eventual smash. Upon judging the shuttlecock's direction and placement by the opponent's return, the player must assume quickly and effectively in order to adjust their stance. The receiving stance, in which the player's feet are shoulder width apart with knees slightly bent and the dominant foot ahead of the other, is quickly changed to a smash waiting stance. The smash waiting stance leads to the acceleration phase and requires that the dominant foot step backwards, with legs spread, with the non-dominant hand and shoulder pointing towards the shuttlecock. The player's dominant foot and shoulder should be in line with the upcoming shuttlecock by pivoting towards right (or racket arm) at the waist and turning the racket shoulder sideways so the player is standing sideways (Aisheng, 2010; Zhao, 2007). The entire movement should be led with the non-racket arm, with the hand pointing up toward the shuttlecock, while the racket arm is also raised with the elbow bent and wrist unlocked so that the racket is pointing upwards (Aisheng, 2010; "How to 10hit", 2014; Zhao, 2007).

\subsubsection{Acceleration Phase (Back-Swing and Forward-Swing)}

The second stage of the forehand overhead smash is called the acceleration phase, which includes a back-swing and forward-swing. The posture begins with the racket arm up and back and then the hand placed behind the player with the players' the upper arm near the right ear, and the elbow pointing up (side view in Figure 4). Additionally, the player faces toward the net with the COG on the front or non-dominant foot(Yang, 2013; Zhao, 2007). The top view (Figure 4) shows a 'shoulder-hip separation' which appears 11 in the trunk segment (Roach \& Lieberman, 2014). During the shoulder-hip separation, the trunk starts to rotate externally and then internally in the smash waiting stance followed by the forearm quickly back-swing, the wrist extends backward and the elbow point up with the racket head pointing down behind the player ("How to hit", 2014; Waddell \& Gowitzke, 2000; Yang, 2013).

The arm movement between the standing and the jump smash is fundamentally the same (Aisheng, 2010). In the jump smash, the same arm movement occurs; the player's body leaps upward, and the COG reaches its highest point during the body's upward movement (Yang, 2013). Once the player finishes the back-swing, the player should initiate a quick forward-swing to make a forceful contact with the incoming shuttlecock ("How to hit", 2014; Yang, 2013). One should swing the forearm forward with the racket head moving upward at the same time ("How to hit", 2014; Waddell \& Gowitzke, 2000). During this procedure, four key points need to be emphasized:

1) Move the racket up to meet the shuttlecock with the elbow leading;

2) Swing racket forward and up to make the contact point as high as possible with an outstretched arm;side view top view Shoulder Hip Line12.

3) Rotate the racket internally and move the racket head downward to make the racket face down;

4) Increase the speed of the upper body through the forward-swing with a fast internal rotation from the back-swing in order to generate more momentum ("How to hit", 2014; Yang, 2013; Zhao, 2007).

\subsubsection{Follow-Through Phase}

The follow-through phase begins after contact. It is executed by rapidly pronating the forearm and flexing the elbow (Waddell \& Gowitzke, 2000). Before the racket head points downward and across the body to rest near the non-racketed leg, the racket head should follow its trajectory and be in line with the flight of the shuttlecock ("How to hit", 2014; Zhao, 2007). As the COG shifts from the back to front foot, the non-racketed shoulder and arm will complete a vigorous leg-scissoring action by left trunk rotation and forward hip flexion. This action propels the player to immediately push off and back toward center court for the preparation of next stroke (Waddell \& Gowitzke, 2000; Zhao, 2007). A good follow-through maintains the racket speed as the player hits the shuttlecock ("How to hit", 2014). As such, using maximum force upon contact will result in an effective follow-through ("How to hit", 2014). In summary, a specific and detailed description of how to execute a powerful smash will be of great interest to coaches, players and scientists. Coaches especially, who do not always see the racket position as described above, will benefit from these visual cues of body movement to ascertain players' performance in order to improve their smash action and to increase the power or accuracy of the smash (Waddell \& Gowitzke, 2000). Hence, studies are needed on the aspects of the player's body such as trunk rotation and body posi

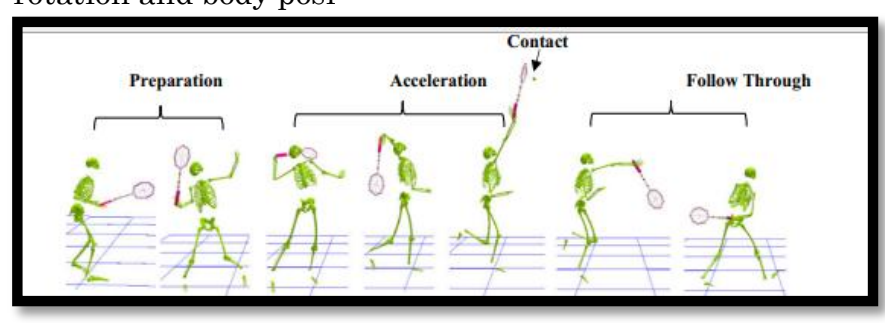

Figure 3. Three Phase Of TheBadminton Forehand Overhead smash with dynamic shuttlecock 
Swell as there are several factors that affect the smash seen from how to train the racket is also needed to do badminton smash "inside artikel The purpose of this study was to develop a methodology that quantifies the contributions of the racket-side upper limb joint torques and shaft restoring torque to the generation of racket head speed during the badminton smash motion, (Wildan, 2011:43).

\subsection{RESEARCH METHODS}

Research and development (reseearch and development / R \& D) according to Borg and Gall in Sugiyono (2008: 9). Mentions that research and development are research methods used to develop or validate products that will be used in education and learning. Research and development can also be used to assess a product in teaching and learning activities. Can the product be used in the world of education or must be revised to be used.

Research and development in this exercise uses the Research \& Development (R \& D) development model of Borg and Gall, (1983: 775) which consists of ten steps including: Conducting research and gathering information (1) literature review, observation of subjects, preparation of subject matter reports) (2) Conducting planning (defining skills, formulating objectives, determining teaching sequences, and small-scale trials) (3) Developing initial product forms (preparation of teaching materials, preparation of handbooks, and evaluation equipment) ) (4) Conducting a preliminary field test (using 6-12 subjects) (5) Making a revision of the main product (according to the suggestions from the results of the initial field test) (6) Performing the main field test (with 30-100 subjects. (7) Revise the product (based on suggestions and results of the main field trials). (8) Test the field with 40-200 subjects (9) Revise the final product (10) Make a report on the product in the journal, work with publishers who can do commercial distribution.

Design R and D Walter R. Borg and Meredith D. Gall, while the effectiveness test of the model empirically involves a wider audience. There are two main objectives of this step: (1) to find out whether the model design has been correctly implemented by the trainer; and (2) how effectively the results of the model design are applied to the research objectives. Based on this explanation, the research at this stage uses a qualitative and quantitative approach. The qualitative approach is used to complement the first objective, while the quantitative approach is used to reveal the second objective, with a pre-experimental research design in the form of the one group pretest-posttest design. Ali Maksum. (2012: 79).

He research sample consisted of badminton athletes in the capital city of Mataram who are members of the UKM Badminton FPOK IKIP Mataram. A total of 100 samples in which 25 students in 2015 were as many as 25 students in the class of 2016, as many as 25 students in 2017 as many as 25 students in class 2018 .
Ased on the evaluation of the field effectiveness group by implementing a badminton smash training model consisting of 15 individual models with all trials. The first stage is the initial test. Then a badminton smash model exercise experiment was conducted for 3 months, so that the final test (post test) was given using a badminton test smash instrument by kunta purnama sapata. The steps taken in this trial include. Data analysis To test the research hypothesis, the statistics used the $\mathrm{T}$ test with a pre-experimental research design in the form of one group pretest-posttest design, Ali Maksum, (2012: 79). And to find out that the training model developed is more efficient, effective and variations can improve the badminton smash (1) determine the research subject group; (2) carry out the pre-test (O1); (3) try the model that has been developed; (4) carry out post-test (O2); (5) looking for the average score of the pre-test and post-test and compared between the two; (6) look for the difference in the second difference between the average through the statistical method (t-test) to determine whether there is a significant effect of the use of the model.

Table 1. Research Design in Model Effectiveness Test.

\begin{tabular}{cccc}
\hline Subyek & Pre-test & Perlakuan & Post-test \\
\hline $\mathrm{R}$ & $\mathrm{O}_{1}$ & $\mathrm{P}$ & $\mathrm{O}_{2}$ \\
\hline
\end{tabular}

\section{RESULTS AND DISCUSSION}

\section{Normality test}

To test the normality of the data used the kolmogorof smirnov test, the calculation using the SPSS release 20 program (C. Trihendradi, 2013: 193). If the calculation results obtained by probability (p) are greater than the level of error (0.05), then the data is normally distributed. The calculation of the variable normality test pre test and post test smash training model in the following badminton games: Based on the table above, obtained the kolmogorov smirnov value for pre-test and post-test data group smash training models in badminton game (X1) of 2,900 with Asymp. Sig. (2-tailed) $=0.00>0.05$, and (X2) of 1,230 with Asymp. Sig. (2-tailed) $=0.00>0.05$, which means the normal distribution model. Based on this analysis shows that the two variable data are normally distributed. 
Table 2. One-Sample Kolmogorov-Smirnov Test

\begin{tabular}{|c|c|c|c|}
\hline & & preetest & postest \\
\hline $\mathrm{N}$ & & 100 & 100 \\
\hline \multirow{2}{*}{ Normal Parameters $\mathrm{a}, \mathrm{b}$} & Mean & 21.0000 & 26.4700 \\
\hline & Std. Deviation & 1.95402 & 3.69672 \\
\hline \multirow{3}{*}{$\begin{array}{l}\text { Most } \\
\text { Differences }\end{array}$} & Absolute & .290 & .223 \\
\hline & Positive & .290 & .223 \\
\hline & Negative & -.290 & -.152 \\
\hline Kolmogorov-Smirnov Z & & 2.900 & 2.230 \\
\hline Asymp. Sig. (2-tailed) & & .000 & .000 \\
\hline
\end{tabular}

a. Test distribution is Normal.

b. Calculated from data.

Test -t (Pre Test and Post Test)

Average Value

Table 3. Paired Samples Statistics

\begin{tabular}{|r|r|r|r|r|}
\hline & \multicolumn{1}{|c|}{ Mean } & \multicolumn{1}{|c|}{$\mathrm{N}$} & \multicolumn{1}{c|}{$\begin{array}{c}\text { Std. } \\
\text { Deviation }\end{array}$} & $\begin{array}{c}\text { Std. Error } \\
\text { Mean }\end{array}$ \\
\hline Pair 1 $\begin{array}{c}\text { preetest } \\
\text { postest }\end{array}$ & 21.0000 & 100 & 1.95402 & .19540 \\
\hline
\end{tabular}

Based on the results of the output using SPSS 20 that the average value before being given is 21000 and after being given treatment with an individual badminton smash training model 26.4700 means that the average value in there is an increase.

\section{Correlation Coefficient}

Based on the results of the table above, the coefficient of the badminton smash training model before and after being given an individual training model is 0.420 with p-value $0.005<0.05$ so the conclusion is significant.

Table 4. Paired Samples Correlations

\begin{tabular}{|c|c|c|c|}
\hline & $\mathrm{N}$ & Correlation & Sig. \\
\hline $\begin{array}{ll}\text { Pair } 1 & \text { preetest \& } \\
& \text { postest }\end{array}$ & 100 & .420 & .000 \\
\hline
\end{tabular}

\section{Test the Difference Significance}

In the significance test of differences with SPSS 20 the results of t-count $=-16,184$ can be obtained, $\mathrm{df}=99$ and $\mathrm{p}$-value $=0.00<0.05$, which means there are significant differences in the exercise model before and after the group training model. Based on the information, it can be said that the training model developed is efficient, effective and can improve the model of smash training for badminton athletes by using an individual training model.

\section{CONCLUSION}

Based on the results of the study, it can be said that the use of an efficiently developed training model can effectively improve the model of individual smash training in badminton athletes. This model of badminton smash training can be applied so that later athletes can be more motivated and varied in doing smashes conducted efficiently, effectively and efficiently by using individual smash models totaling 15 training models based on more valid basics based on the presentation analysis of the evaluation results by the test subjects with the badminton smash training model that the researchers have developed in accordance with the basic motion, it shows that there is a significant increase. That the model of forehand smash training in Badminton games made by researchers can be applied individually to smash, because the results of the data obtained are valid based on the analysis of the presentation and the results of evaluations by the test subjects. Thus suggestions for the use of desemination and development of this product further towards the development of this Badminton training model.

\section{REFERENCES}

Aksan, Hermawan. (2013) Mahir Bulutangkis. Bandung: Alfabeta.

Barnamehei, at al. (2018). Upper Limb Neuromuscular Activities and Synergies Comparison between Elite and Nonelite Athletics in Badminton Overhead Forehand Smash. Jurnal Hindawi Applied Bionics and Biomechanics Volume 2018, Article ID 6067807, 10 page.

Borg. W.R \& Gall, M.D, (1983). Education Reseach An Introduction. New York: Longman.

Borg, W,R \& Gall, M.D. Gall. (2005). Educational Research: An Intriduction, Eight Edition. New York: Longman.

Lung-Ming Chen at. Al. (2009). A study of shuttlecock's trajectory in badminton: Journal of Sports Science and Medicine (2009) 8, 657-662 http://www.jssm.org

Maksum, Ali. (2017). Metode Penelitian Dalam Olahraga .Surabaya:Unesa

Matsunaga N. at al. (2018). Comparison of Modular Control during Smash Shot between Advanced and Beginner Badminton Players. Jurnal Hindawi Applied Bionics and Biomechanics. 2018

Michal Wilk, at., al. (2019). The Effects of Eccentric Cadence on Power and Velocity of the Bar during the Concentric Phase of the Bench Press Movement. Journal of Sports Science and Medicine.18(1) 191-197 http://www.jssm.org.

Muhammad Ilhamdi Rusydi, at al, (2015). Local Euler angle pattern recognition for smash and backhand in badminton based on arm position. 6th International Conference on Applied Human Factors and 
Ergonomics (AHFE 2015) and the

Affiliated Conferences, AHFE 2015 Procedia Manufacturing 3 ( 2015 ) 898 - 903

Purnama, S. K. (2010). Kepelatihan Bulutangkis Modern. Surakarta:Yuma Presindo.

Roesdiyanto dan Setyo Budiwanto. (2008). Dasar-dasar Kepelatihan Olahraga. Malang: Laboratorium Ilmu Keolahragaan-Universitas Negeri Malang.

Sayed Kavos Saleh, at., al. (2017). Comparison Exam of Gallahue's Hourglass Model and Clark and Metcalfe's the Mountain of Motor Development Metaphor. Advances in Physical Education, 2017, 7, 217-233 http://www.scirp.org/journal/ape ISSN Online: 2164-0408 ISSN Print: 2164-0386

Sugiyono. (2008). Metode Penelitian, Pendekatan kuantitatif, kualitatif dan R\&D Bandung. Alfabeta.

Widiastuti. Tes dan Pengukuran Olahraga. Jakarta, 2015.

Zhao Zhang. (2012) The Influence Of Body Positioning, Trunk Rotation (X-Factor) And Training

Effect On Quality Of The Badminton Forehand Overhead Smash (Thesis). University Of Lethbridge Lethbridge, Alberta, Canada

Xiaoxue Zhao and Shudong Li, (2018). A Biomechanical Analysis of Lower Limb Movement on the Backcourt Forehand Clear Stroke among Badminton Players of Different Levels. Jurnal Hindawi Applied Bionics and Biomechanics Volume 2019, Article ID 7048345, 8 pages https://doi.org/10.1155/2019/7048345 